to readjust it; but as to conversation, I could enter into none in the absence of the general practitioner. No cases demand more consideration than those of ununited fracture. Union may fail from constitutional causes, in spite of the best treatment; bnt whatever opinion a consultant may form on that point, his clear course is to do all he can to repair the bone without incurring the risk of breaking the practitioner. My patient's nephew made a few more attempts, but he very soon perceived that, if his case was to rest on me, he could entertain very poor hopes in bringing an action for compensation, of which I heard no more.

That consultations, rightly conducted, are as much in the interest of the profession as of the public,-that too fer consultations are held, and at too late a period in the progress of many cases, - that it is a mistake to suppose that division of responsibility necessarily involves division of reward in reputation and fees,-are general propositions of the truth of which no impartial observer can entertain a doubt.

How different the state of affairs in the legal profession. In almost every case of difficulty, and at succeeding stages from its very commencement, a solicitor takes counsel's opinion; aud, if a case go to trial, a number of counsel are generally engaged on both sides. But it is only just to bear in mind that the relative position of solicitor acd counsel is so clearly defined, and the rules of the Bar are so binding, that legal practitioners can afford to be just to their clients and generous to their brethren, without imperiling their individual interests. What chance would there be of equity counsel being consulted by solicitors on knotty questions of property law, if there were any risk of the former supplanting the latter in the management of estates? It is no use framing rules of professional morality in opposition to the dictates of common sense; and it is not to be expected of any men that they will act in opposition to the instinct of self-preservation. Our first aim should undoubtedly be a patient's welfare; but members of the profession cannot have too scrupulous a regard for the legitimate susceptibilities and rightful interests of their brethren; and these remarks apply not merely to the relations between consultants and general practitioners, but to those between hospital physicians and surgeons practising general and special departments. It is even truer now than when Pope wrote-

$$
\begin{aligned}
& \text { "One science only will one genius fit, } \\
& \text { So vast is art, so narrow human wit; } \\
& \text { Not ouly bounded in peculiar arts, } \\
& \text { But oft in these confined to single parts." } \\
& \text { Essay on Criticism. }
\end{aligned}
$$

It must be admitted that, in spite of the utmost care, it is impossible to steer clear of difficulties. When our opinions differ, a host of seribblers, who call themselves literary men for no better reason than that they live by writing, are ever ready with the famous truism, "when doctors differ......"; forgetting that the very construction of our courts of law, from courts of first instance to courts of error, and the highest tribunals for appellate jurisdiction, is to provide for differences of opinion, amongst learned men, of ten on the simplest matters of fact and with the clearest legal precedents. But, in justice to the scribblers, they are not our only detractors. Molière's satires against doctors have passed into proverbs, and, though the laugh is against us, it is impossible not to enjoy the pungent wit of the amour snédecin.

The taunt of proneness to differ in opinion is, after all, not so harmful as the charge of jealousy, which is certainly one of the commonest of human failings. A rather extensive acquaintance with men in most callings of life has convinced me that, if we except lawyers, the men of no class, be it ministers of religion or men of letters, statesmen or soldiers, artists or artisans, are less embittered or hampered by jealousy than our professional brethren. If two blacks do not make a white, $\grave{a}$ fortiori ten or a thousand do not; and we must all agree that to uproot petty jealousies and to encourage generous rivalry in the most catholic spirit should be our constant aim ; and, while working at our own advancement, let us unite in repelling the charges often so inconsiderately brought against us. An anecdote in point may be excused. It recently happened that several distinguished physicians and surgeons differed in an important case, in which one of our leading manufacturers took great interest; and he is in the front rank, not merely for the magnitude of his works and for reputed wealth; he really can talk Eng- lish and knows something besides. Talking over with me the difference which had become apparent after the consultation, he exclaimed, "All owing to professional jealousy." I merely remarked, which I was able to do most conscientiously, that the case afforded an instance of legitimate difference of opinion, honestly expressed. "By the bye," I suddenly interpolated, "I have a favour to ask you. I have some friends here from abroad, who take a great interest in manufactures: one of them is a skilled engineer, a clever draughtsman, and a very enterprising man. May I have the pleasure of introducing then to you to-morrow at your works, in order that they may enjoy the privilege of inspecting them ?" "I am always happy to oblige you," rejoined the manufacturer-and I quote his answer literally,- " but we have a large amount of patent machinery which we never show to strangers." I assured him that any physician or surgeon from any part of the world would be welcome to go over our hospital or any similar institution in the kingdom, and might rely on having access to all the records for any information he might be desirous of obtaining. We can well afford to smile at taunts of jealousy, from manufacturers at any rate.

In one sense, but only in one, let us plead guilty to the impeachment of jealousy-for our professional honour; and let our energies be devoted to proving that the best interests of the profession are one with the best interests of the public, and that both may be promoted by directing with wise liberality the economy of consultations.

Birmingham.

SUCCESSFUL REMOVAL OF THE TESTICLES, SCROTUM, PENIS, AND SUPRAPUBIC SKIN FOR EPITHELTAL CANCER.

Bx THOMAS ANNANDALE, F.R.S.E., SURGEON TO THE FDINBURGH INFIRMARY, AND LBCTURBR ON CLIMICAL SURGREY.

Peter R-, aged thirty-one, was admitted into my wards on Oct. 7th, 1873, on account of epithelial cancer affecting the genital organs. The disease had originated in the extremity of the penis four years ago, and had since gradually implicated the surrounding parts. On admission, the greater portion of the penis had been destroyed by the disease, an ulcerated mass of epithelial cancer occupying the position of the organ. The greater part of the scrotum was involved in the disease, which had destroyed the superficial tertures, and become adherent to the testicles. The skin and cellular tissue over the pubes were also affected with the disease to an extent of rather more than two square inches. The entire disease presented the appearance of a large, irregular, ulcerated surface, implicating the parts enumerated, with hardness and discolouration of the tissues forming the circumference of the sore. There were one or two glands slightly enlarged in the right groin, but this enlargement appeared to be the result of simple irritation, and was only of recent origin. The patient had much difficulty and pain in passing water. His general condition of health was fair, but he noticed that he was becoming markedly emaciated.

As it seemed to me possible to remove the entire local disease, and as the patient's strength was considered good enough to admit of an operation which did not involve any great loss of blood, I undertook, with his consent, to remove the diseased parts after a careful consideration of the case.

On the 15 th of October I performed the operation in the following manner. An incision being made over the external abdominal ring on one side, the spermatic cord, including its vessels, was carefully cleared, and, a ligature of strong silk having been placed round it, it was cut through below the ligature. The same proceeding was adopted on the opposite side, and then the root of the penis, having been exposed by dissection as far back as possible, was cut across, a temporary ligature being first passed round it. In this way the testicles and diseased remnant of the penis were detached, and all bleeding from their vessels was prevented. The next step consisted in dissecting away the whole disease and a margin of healthy texture from the scrotum and 
suprapubic region, including the detached organs. The vessels of the penis were now secured separately, and any other vessels which bled were also tied. The result of the operation was a very large wound, the edges of which could not of course be brought together, but a few stitches through the perineal portion slightly diminished this part of the wound. The whole wound was freely sponged with De Morgan's solution of the chloride of zinc, and lint soaked in carbolic oil was applied over it.

Oct. 23rd.-The patient's progress since the operation has been most satisfactory. His temperature is now normal, and his general health is improving. The wound continues to be dressed with carbolic oil, which is renewed every two hours.

Nov. 1st. - The general condition and wound are still progressing favourably; the latter is steadily contracting. The orifice of the urethra remains free, and the patient passes urive easily and without pain.

Dec. 30th.-To-day the patient was dismissed cured, and much improved in health, his emaciation having quite disappeared. The wound is now healed, and the orifice of the urethra remains open, so that there is no difficulty in passing urine. It is also noted that the glandular enlargement has much diminished.

The patient promised to report if any return of the disease took place; but as up to this date (December, 1874) he has not been heard of, it is understood that he remains well.

Remarks.-This case is encouraging in connexion with the treatment of epithelial cancer, and proves that a serious operation may be successfully performed for its relief, provided that the entire disease can be removed, and the patient's condition admits of such a proceeding. The duration of the disease and the marked improvement of the patient's health after its removal point very ảecidedly to the local nature of the cancer in this case. The prevention of hæmorrhage during the operation was an important question in this case, for it is well known that the vessels connected with the genital organs bleed freely when divided. The method adopted in the present instance for restraining the hæmorrhage was most successful, and the operation was completed with a comparatively slight loss of blood-a circumstance which no doubt assisted in promoting the excellent recovery of the patient.

Edinburgh.

\section{NOTES ON THE}

\section{LOCAL USE OF LIQ. FERRI PERCHLORIDI FORTIOR IN CANCEROUS ULCERA- TIONS OF THE UTERUS.}

By CHARLES J. GIBB, M.D., CONSULTING SURGEON TO THE NEWCASTIE INFIRMARY.

Cancerous diseases of the uterus have generally progressed so far before they come under professional observation as to pass as incurable from one medical man to an. other; and it thus happens that I see a large number in my consulting rooms. It is rare to find the disease so superficial and purely epithelial in character, or, if interstitial, so confined to the mouth and neck of the uterus, that the diagnosis can be made with such certainty as to justify the surgeon in excising it; and, in the advanced stages, the foul discharges make the case so loathsome that, in spite of the keenest feelings of pity, the surgeon is inclined to view the case as utterly hopeless, and to leave all nianual treatment to the nurse. When we remember how nuch relief can be given to the worst symptoms of the most incurable cases of external cancers by operation, or other measures calculated to remove fungoid or sloughing surfaces or masses of the disease; how pain can thus be relieved, bleeding prevented, foul discharges moderated or made less disgusting in character,-it is not surprising that surgeons should strive to give similar relief to the worst cases of cancer of the womb, and be more or less successful in their efforts. From time to time I have tried the various local applications I have seen recommended, have made use of many caustics, been taught by painful experience that caustic potash or caustic potash and lime are unmanageable and too dangerous to the surrounding parts to be used with the freedom requisite to be of service, that the actual cautery is too fear-inspiring, that nitric acid and acid nitrate of mercury (which have to be used with great care) are inefficient, and that lunar caustic and powders or points of alum are useless as caustics.

About two years ago I had occasion to dilate the uterus in a very obstinate case of menorrhagia, proceeding from large vascular granulations in the cavity of the enlarged organ. The strongest Pharmacopoial solution of the perchloride of iron (being, in fact, iron dissolved in pure acid) was injected into the open uterine cavity, and a piece of sponge soaked in the solution left there for twenty-four hours. This treatment was perfectly successful; and I viewed with surprise the efficient way in which the soft and vascular growths were destroyed, whilst the normal structures of the uterus and vagina were but little inconvenienced, and certainly not in the least eroded. Since that time I have been accustomed to use this solution in many cases of cancer of the uterus; and I jotted down the histories of the following four cases, being cases of cancer in which $I$ used it in my consulting rooms during one week.

CASE 1. - Mrs. B- aged thirty-six; a shopkeeper; married five years; no children. Was a strong, powerful woman until fourteen months ago, when she was seized with menorrhagia, followed by the foul sanious discharges and other symptoms of cancerous ulceration. She came to my offices six weeks ago, anæmic to the last degree from almost constant bomorrhage and putrid discharge. On examination, the mouth and neck of the uterus were found destroyed, and their place occupied by a large, deep, sloughing, cancerous sore. The body of the uterus felt greatly enlarged and as hard as a cricket-ball, whilst the vagina was quite free from disease. Profuse hæmorrhage attended the examination. The sore was filled with cotton-wool soaked in the solution of the perchloride, and the vagina stuffed with tow. She came from a distance by rail, and was ordered to remove with her fingers, or allow the lady who accompanied her to withdraw, the stuffing of tow next morning, and trust to the injections of zinc and alum to wash away the cotton-wool ; and appropriate blood-making and aperient medicines were prescribed. On her second visit she expressed herself as much stronger, very little bleeding having taken place during the week. The application of the perchloride was repeated, and I did not see her for the next ten days, in consequence of a severe attack of pain compelling her to remain in bed. The sore was much healthier in appearance, there had been very little bleeding, and the discharge had become scanty and semi-purulent in appearance, without any of the old foul, putrid smell. She was, however, very feeble, and made the journey with great difficulty. Instead of placing the cotton-wool soaked in the perchloride over the sore, I elevated her breech, half filled the vagina with the solution for a couple of minutes, then sucked it up with a syringe, and left a plug of tow in the vagina, to be removed next day. The improvement was marked on her fourth visit; and on her sixth I found there had only been a little bleeding once during the week, whilst forcing away a very costive motion. The ulcer was perceptibly smaller and free from slough, the circumference of the vagina around it having contracted considerably. A small quantity of yellow, oil-like pus lay in the vagina, but the examination still caused the ulcer to bleed slightly. The ulcer was again bathed with the strong perchloride, and she returned home, expressing herself as twice as strong as when she first called upon me, and very much relieved from the local misery.

CASE 2.-Mrs. R-, aged thirty-six, an innkeeper, with several children, the last seven years old. Began to have menorrhagia and the ordinary symptoms of cancer of the womb nearly a year ago. Commenced attending my offices four montbs ago. Was found to have a large, soft, bleeding epithelioma, covering the swollen and apparently destroyed vaginal part of the uterus, and extending along the front wall of the vagina to within an inch and a half of the orifice of the urethra. She came in a cab, and her linen was drenched with blood. She was excessively anæmic from daily hæmorrhage, and was evidently in the last stage of the disease, the sore bleeding on the least examination. A large piece of cotton wool was soaked in the perchloride, placed over the disease, and the vagina stuffed with tow. 